\title{
Biosynthesis of Metal Nanoparticles: Novel Efficient Heterogeneous Nanocatalysts
}

\author{
Jose M. Palomo ${ }^{1, *}$ and Marco Filice ${ }^{2}$ \\ 1 Departament of Biocatalysis, Institute of Catalysis (CSIC), Marie Curie 2, Cantoblanco, Campus UAM, \\ 28049 Madrid, Spain \\ 2 Advanced Imaging Unit, Spanish National Research Center for Cardiovascular Disease (CNIC), \\ 28049 Madrid, Spain; mfilice@icp.csic.es \\ * Correspondence: josempalomo@icp.csic.es; Tel.: +34-91-5854768; Fax: +34-91-5854670
}

Academic Editors: Hermenegildo García and Sergio Navalón

Received: 17 February 2016; Accepted: 26 April 2016; Published: 5 May 2016

\begin{abstract}
This review compiles the most recent advances described in literature on the preparation of noble metal nanoparticles induced by biological entities. The use of different free or substituted carbohydrates, peptides, proteins, microorganisms or plants have been successfully applied as a new green concept in the development of innovative strategies to prepare these nanoparticles as different nanostructures with different forms and sizes. As a second part of this review, the application of their synthetic ability as new heterogonous catalysts has been described in $\mathrm{C}-\mathrm{C}$ bond-forming reactions (as Suzuki, Heck, cycloaddition or multicomponent), oxidations and dynamic kinetic resolutions.
\end{abstract}

Keywords: metal nanoparticle; biosynthesis; peptides; sugars; proteins; heterogeneous catalysis

\section{Introduction}

Nanotechnology has experimented a tremendous rise in the last decade [1-4]. In particular, the design of nanoparticles (NPs) has represented a very promising strategy alternative to conventional processes, especially of great application in environmental and biomedical problems (such as drug delivery, imaging, etc.) [5-8].

However, the field of nanocatalysis focused on the use of nanoparticles ashomogeneous or heterogeneous catalyst has been growth during the last years, [9-13]. The large surface-to-volume ratio of nanoparticles compared to bulk materials makes them attractive candidates for its use as catalysts. Especially the preparation and characterization of NPs from noble metals, which constitutes an important branch of heterogeneous catalysis in the chemical industry, represents an important challenge. The advantages of a very high superficial area make them excellent catalysts, reducing the amount of catalyst per gram of product making the process more sustainable. These NPs are synthesized by chemical methods in such a way to obtain good amounts, controlling the size and the form of the NPs [14-16]. However, in most cases hazardous conditions are used, toxic solvent, high amounts of energy $\left(200^{\circ} \mathrm{C}\right)$, which reduce a possible industrial implementation of this nanocatalyst. Most of these methods are still in the development stage and problems are often experienced with stability of the prepared nanoparticles, control of the crystal growth and aggregation of the particles [14-16]. Therefore the design of new synthetic approaches which considering an easy, rapid and sustainable strategy represents an important issue.

In recent years, a number of new green strategies have been described in literature. They are based on the capacity of biomolecules to induce the formation of these nanoparticles, sometimes even controlling the size and the structural form, and avoiding aggregation problems [17-27].

In this way, small molecules such as monosaccharides (glucose or galactose), or aminoacids and short peptides has been used as reducing agent for in situ creation of these metallic 
nanoparticles [17-21]. In addition, in a more precise way, the application of more complex biomolecules such as proteins or even microorganisms have been successfully applied to create nanoparticles and also hybrid systems with very high potential catalytic properties [23-26]. Bionanostructures, in which an enzyme is specifically encapsulated in a nanocluster or immobilized on biofunctionalized nanoparticles [10] are another category of catalysts with excellent features in cascade reactions. In particular, heterogeneous enzyme-metal nanoparticle nanohybrids with multiple catalytic activies are interesting in organic synthesis.

In this review, an overview of the recent advances on these new biosynthetic strategies and the use of the formed nanoparticles as catalyst in chemical processes is shown.

\section{Synthesis of Metal Nanoparticles Induced by Glucosides}

The most recent strategies targeting the synthesis of metallic nanoparticles have expected the introduction of green methodologies. In this sense, the use of glycosides avoids the necessity to apply toxic materials.

Thus, green synthesis of NPs induced by glucose and different glycopyranosides has been successfully reported $[18,19,28]$. In this case, very interesting results were found in the synthesis of gold nanoparticles (AuNPs) using eight different glucose derivatives [27].

A room temperature and easy synthetic method of AuNPs was developed using auric acid, sodium hydroxide and different glycosides as reducing agent (Figure 1).

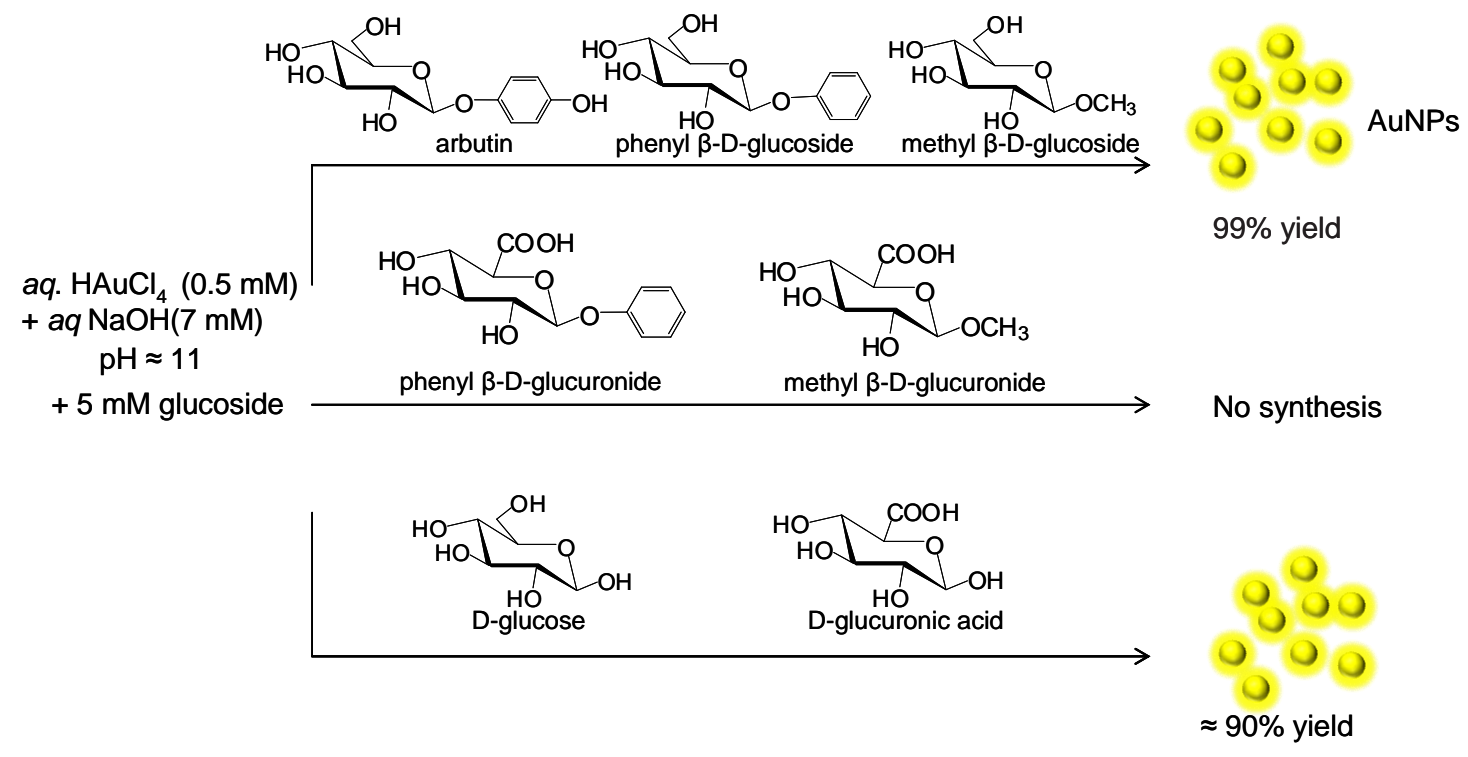

Figure 1. Synthesis of gold nanoparticles (AuNPs) induced by different glucose derivatives.

Eight sugar-containing reductants were used for comparison. C-6 position of glycosides was oxidized to a carboxylic acid during the reduction of auric acid in the formation of AuNPs in the case of sugars substituted at the anomeric carbon/position (Figure 1). In the case of glucose or glucuronic acid (COOH in C-6), the NPs formation may be due to the oxidation of an aldehyde generated via anomerization. In this way, this explains why the synthesis in the presence of the glucuronic acid derivatives substituted at the anomeric position did not work (Figure 1).

Furthermore, significant differences in the final yield in AuNPs and especially the form and the size of the nanoparticles obtained by high resolution transmission electron microscope (HRTEM) (from 8 to $27 \mathrm{~nm}$ ) depended on the sugar derivative (Figure 2).

The use of 1-phenyl or 1-methyl- $\beta$-glucopyranoside gave the highest synthetic yield ( $>99 \%$ ) of homogeneous mono-dispersed round gold nanoparticles $(13.15 \mathrm{~nm}$, or $10.95 \mathrm{~nm}$ respectively), whereas 
using glucose or glucuronic acid the synthesized AuNPs showed multiple forms (16 and $8.8 \mathrm{~nm}$ ). In the presence of arbutin, nanoparticles showed an amorphous form (27.4 nm) (Figure 2).

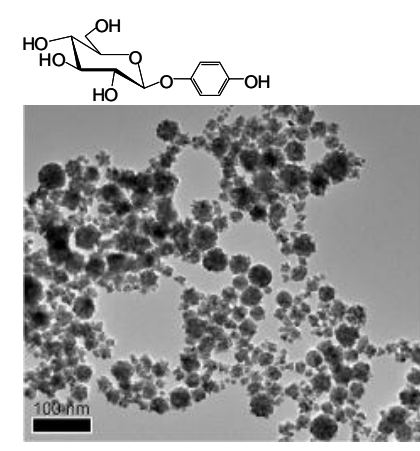

$27 \pm 16 \mathrm{~nm}$

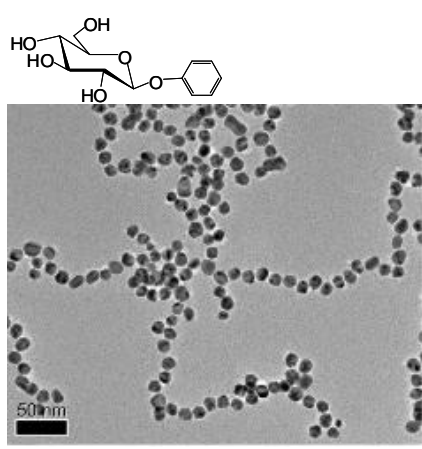

$13 \pm 1 \mathrm{~nm}$

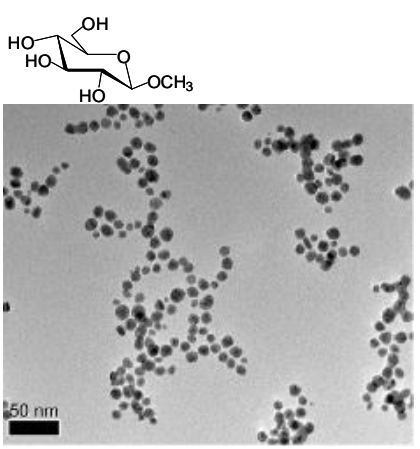

$11 \pm 2 \mathrm{~nm}$
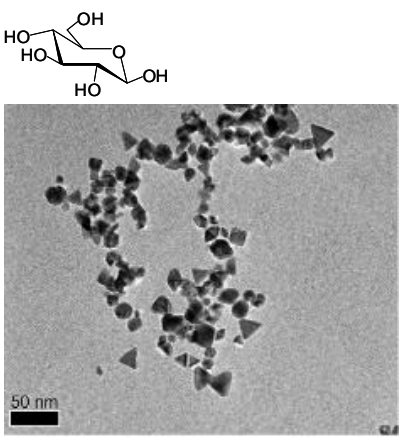

$16 \pm 4 \mathrm{~nm}$
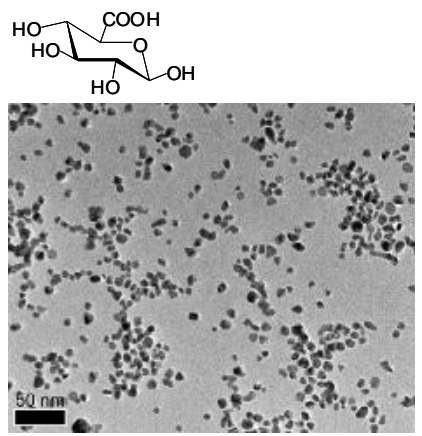

$9 \pm 2 \mathrm{~nm}$

Figure 2. Characterization of the glucoside-induced AuNPs by high resolution transmission electron microscope (HRTEM).

Therefore, this work shows how the size and the form of gold nanoparticles can be controlled by using different sugars as additives. This aspect is of special interest for example in the case of ultrasmall nanoparticles, where their colloidal stability can be affected by these small size differences, underscoring the importance of particle uniformity in nanomedicine [28].

These strategies could be also extended with other metals and also using other sugars derivatives with different degree of hydrophobicity by substitution in the anomeric and other positions.

In a recent approach, AgNPs were synthesized using aqueous extract of Clerodendron serratum leaves, which have high contents of polyphenol glycosides and quercetin 3-O- $\beta$-D-glucoside [29].

This glucose derivative caused the reduction of the silver ions of silver nitrate in $30 \mathrm{~min}$ at room temperature, forming spherical AgNPs with the size range of 5-30 nm (Figure 3A). In addition, the strategy of using glycosides has been successfully used in the preparation of mesoporous nanostructures [30].

Mesoporous silica-coated silver nanoparticles (Ag@MSN) have been prepared by a two mild step synthesis. Glucose was used as reducing agent for silver ions whereas arginine was used for the formation of silica. The nanostructure presented single $\mathrm{Ag}$ nanoparticles as cores of diameter $\mathrm{ca} .30 \mathrm{~nm}$ surrounded a silica shell (thickness of $c a .30-40 \mathrm{~nm}$ ), with a total average particle size (ca. $110 \mathrm{~nm}$ ) (Figure 3B). 

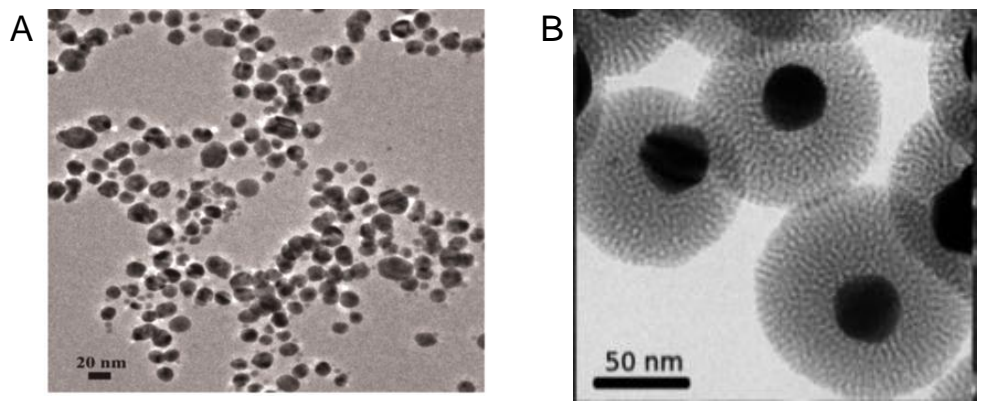

Figure 3. TEM image of different AgNPs. (A) AgNPs; (B) Mesoporous silica-coated silver nanoparticles (Ag@MSN) coated on a silicon substrate.

Another interesting example is the creation in situ of glycosylated functionalized gold nanoparticles [31].

In this case, the glycoside acted as reducing agent but also is a specific moiety for particle functionalization. A glycopolymer (cellulose) was activated in the anomeric position by thiosemicarbazide producing glucoside thiosemicarbazone (Figure 4A). This activated sugar combined with an aqueous $\mathrm{N}$-methylmorpholine $\mathrm{N}$-oxide (NMMO)-a molecule which permits the solubilization of the water-insoluble cellulose- and a dilute aqueous $\mathrm{HAuCl}$ solution finally producing glyco-AuNPs. TEM analysis confirmed the formation of AuNP aggregates with primary sizes of ca. $10-20 \mathrm{~nm}$ in diameter (Figure 4B). Same protocol was used to successfully synthesize glyco-AgNPs with distribution size of $c a$. 5-30 nm diameters.

The combination of NMMO-mediated GNP synthesis and immobilization of sugar reducing ends to an $\mathrm{Au}^{\circ}$ matrix, allowed the design of a diverse array of carbohydrate-GNP conjugates by tailoring the functional sugars, e.g., cellulose, chitin, chitosan, maltose and lactose [18].

A
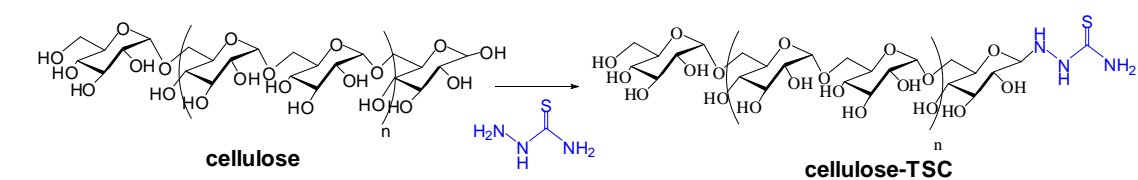

$\mathrm{HAuCl}_{4}$

$+\mathrm{N}$-methylmorpholine

$\mathrm{N}$-oxide

B
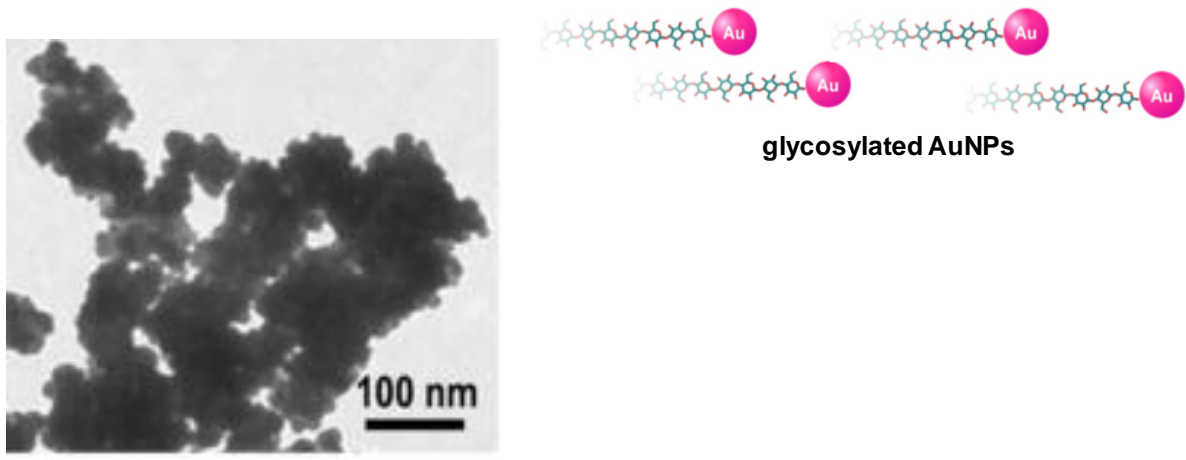

glycosylated AuNPs

Figure 4. Synthesis of glycosylated AuNPs. (A) Synthetic scheme; (B) TEM image of glyco-AgNPs.

\section{Biosynthesis of Metal Nanoparticles by Peptides}

The synthesis of biocompatible metal nanoparticles can be performed by using peptides as multifunctional reagents (reducing and capping agents) under mild conditions [32-36]. The large 
diversity of peptides available provides a new opportunity to organize, interact, and direct the shape, size, and structure evolution of the metal nanoparticles in more varied and innovative ways. In some cases these peptides also show the capability to reduce metal ions and to template the crystal growth of the metal nanoparticles [37].

The use of a short conjugated peptide, such as a biotinylated di-tryptophan peptide was applied by Mishra and coworkers for the one-pot synthesis of stable gold nanoparticles [32]. The tryptophan dipeptide stabilized the NPs generated with an average size between 4 and 6 nm. Furthermore, self-assembled superior and ordered nanostructures of variable size were afforded where the AuNPs were scattered inside the biotinylated spherical scaffold in a controlled manner (Figure 5).

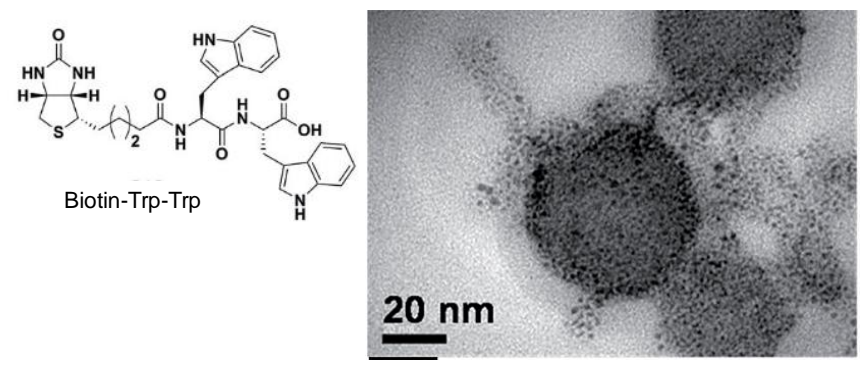

Figure 5. Self-organized AuNPs on the surfaces of biotin-Trp-Trp scaffold.

In another strategy, Giese et al. have recently described the synthesis of AgNPs under electron transfer conditions [33]. $\mathrm{Ag}^{+}$ions are bound by a peptide including a histidine (Figure 6A) as the Ag-binding amino acid, and a tyrosine as a photo inducible electron donor. The presence of chloride ions was necessary for the final formation of AgNPs, which occur on $\mathrm{AgCl}$ microcrystals in the peptide matrix. In this way, by controlling the irradiation times, the formation of $\mathrm{Ag} @ \mathrm{AgCl} / \mathrm{peptide}$ nanocomposites with a sized of $100 \mathrm{~nm}$ at the beginning of the process was obtained, which are cleaved after time finally generating the AgNPs with a diameter of $15 \mathrm{~nm}$ (Figure 6).

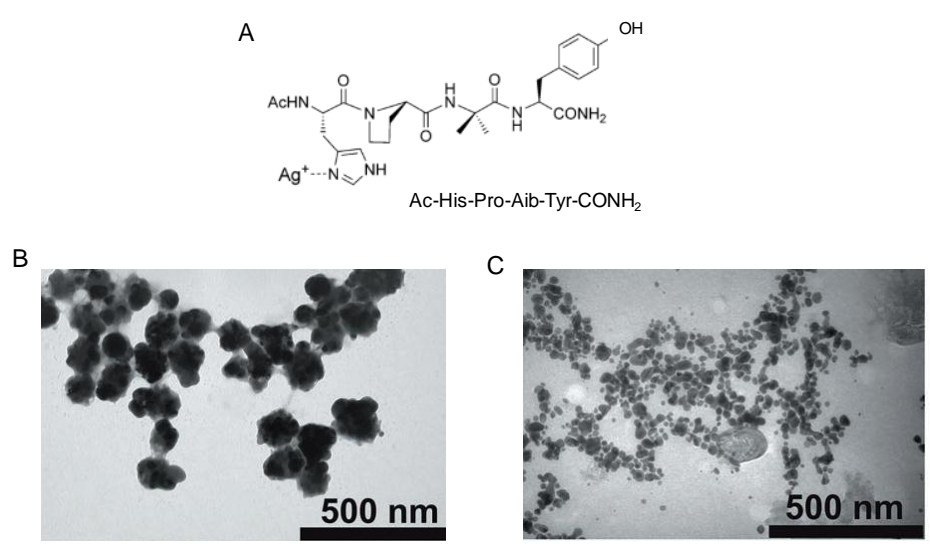

Figure 6. Synthesis of AgNPs. (A) Peptide structure; (B,C) TEM pictures $\mathrm{Ag}^{+}$-peptide complex after different irradiation times, $t=30 \mathrm{~s}$ and $t=30 \mathrm{~min}$, respectively.

Tekinay and coworkers described the design and application of a multidomain peptide for single-step, size-controlled synthesis of biofunctionalized AuNPs (Figure 7) [34]. Size-controlled synthesis of AuNPs with this peptide was possible due to the 3,4-dihydroxy-L-phenylalanine (L-DOPA) functional group, a residue known for its reductive role. The authors showed DOPA coupled its oxidation to the reduction of $\mathrm{Au}$ (III) ions, thereby leading to the formation of biofunctionalized AuNPs. Hence, the DOPA-mediated peptide design enables concerted one-pot reduction, stabilization and functionalization of resulting AuNPs whereby no additional reagent or reaction is needed. 

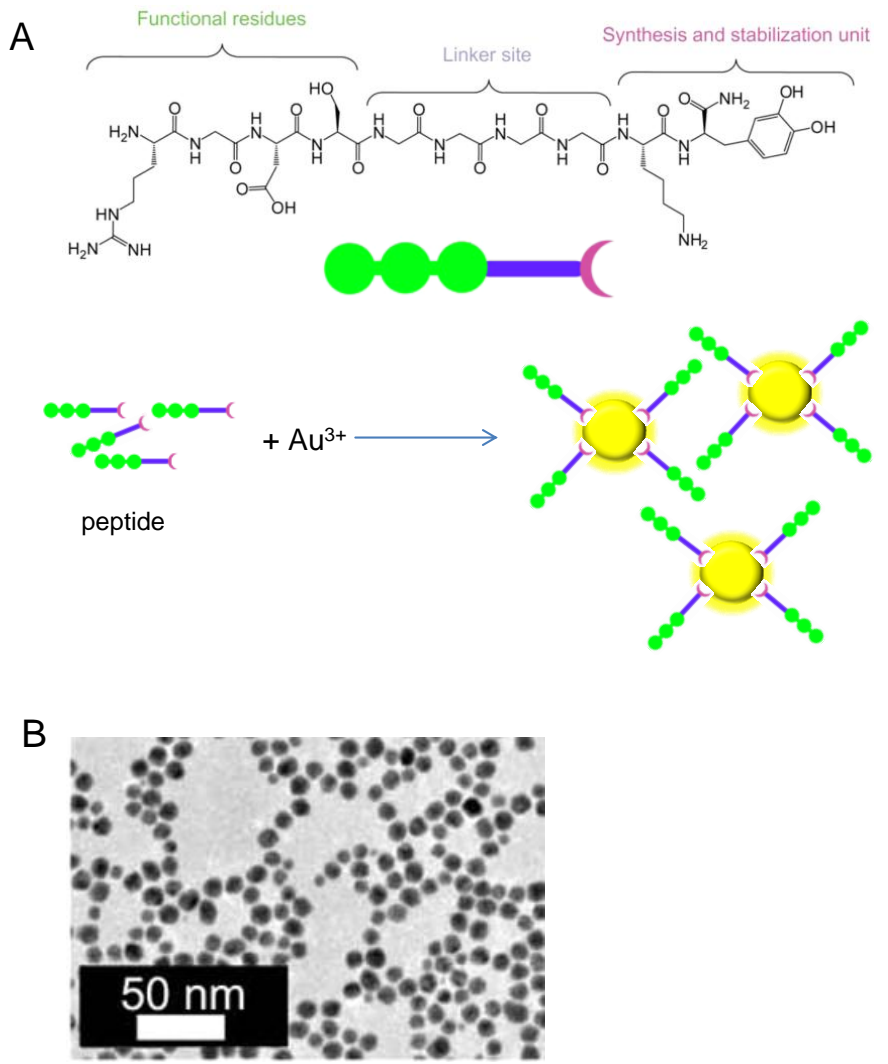

Figure 7. Synthesis of Biofunctionalized AuNPs. (A) Peptide and scheme of NPs formation; (B) TEM images of the AuNPs.

\section{Bio-Inspired Synthesis of Nanoparticles by Proteins}

Among these strategies, the employment of microbial enzymes for nanoparticle synthesis is a new field with growing importance. In fact, considering that various enzymes have different capacities for synthesis of nanoparticles in a wide set of shapes and sizes, it is very important to find suitable enzymes for such purposes and improve the method for optimal nanoparticle production. Conversely, nanoparticles obtained by cell-based methods forcefully bind to the microbial biomass resulting in high-cost laborious steps of separation and purification of nanoparticles from microbial cells. In this line, many examples have been reported in literature. For example, Cholami-Shabami et al. developed a cell-free viable approach for synthesis of gold nanoparticles using NADPH-dependent sulfite reductase purified from Escherichia coli. [38] Highly stable gold nanoparticles were produced by reductive process after application of the sulfite reductase to an aqueous solution of $\mathrm{AuCl}_{4}{ }^{-}$. The enzymatically synthesized gold nanoparticles showed strong inhibitory effect towards the growth of various human pathogenic fungi [38]. Another interesting approach was developed by Kas and coworkers permitting the achievement of nanosilica-supported Ag nanoparticles by means of a biosynthetic protocol (Figure 8) [39]. After immobilizing a protein extract proceeding from Rhizopus oryzae on the surface of a nanosilica structured support, the authors carried out the synthesis of AgNPs using this biohybrid as host for the growth of AgNPs on its surface. In the proposed in situ synthetic process, the $\mathrm{Ag}^{+}$ions-proceeding from an $\mathrm{AgNO}_{3}$ solution as metal precursorwere considered to be rapidly adsorbed on negatively charged protein surfaces through electrostatic interaction. The reduction of $\mathrm{Ag}^{+}$ions and the subsequent formation of AgNPs was due to the electron transfer between the metal ions and the functional groups of proteins. 
A

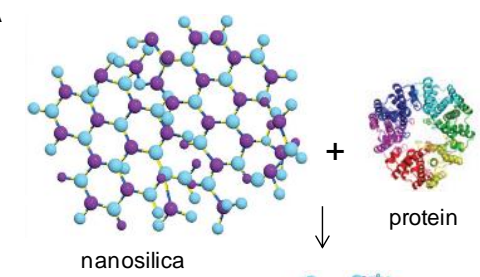

nanosilica

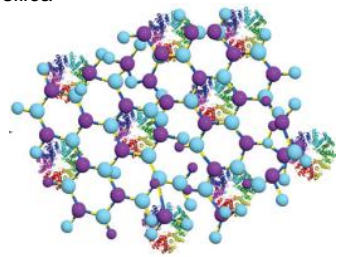

B
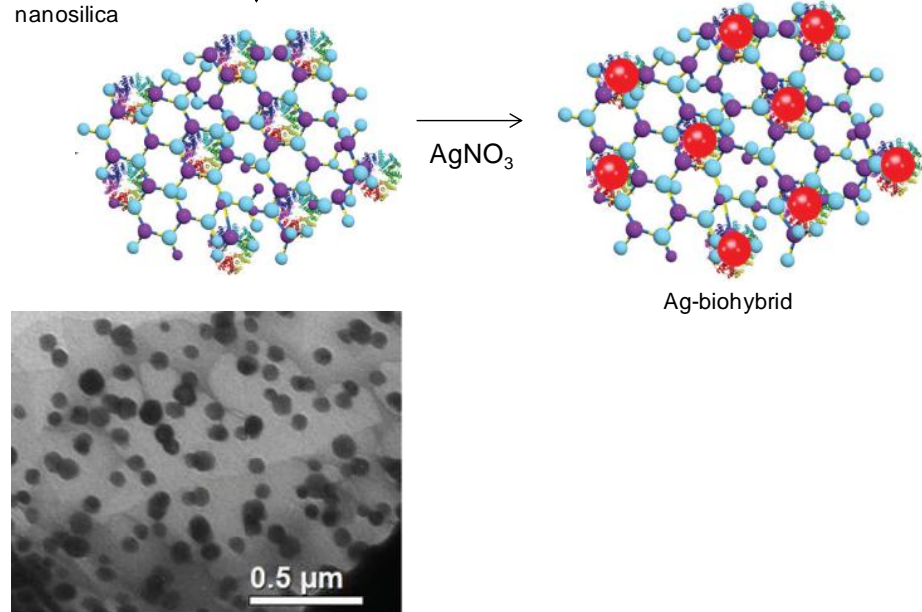

Ag-biohybrid

Figure 8. Synthesis of Ag-biohybrid. (A) Scheme of the formation of the nanostructure; (B) TEM of Ag-nanohybrid. Reproduced with permission from [39]. Copyright the Royal Society of Chemistry, 2013.

Following this research line, a novel type of heterogeneous hybrid nanocatalysts, composed by metal NPs embedded in an enzymatic net, was generated in situ under very mild reaction conditions from the simple mixture of lipase from Candida antarctica fraction B (CAL-B) with a homogeneous aqueous solution of a noble metal salt $\left(\mathrm{Ag}^{+}, \mathrm{Pd}^{2+}\right.$, or $\left.\mathrm{Au}^{3+}\right)$ (Figure 9) [22,40].

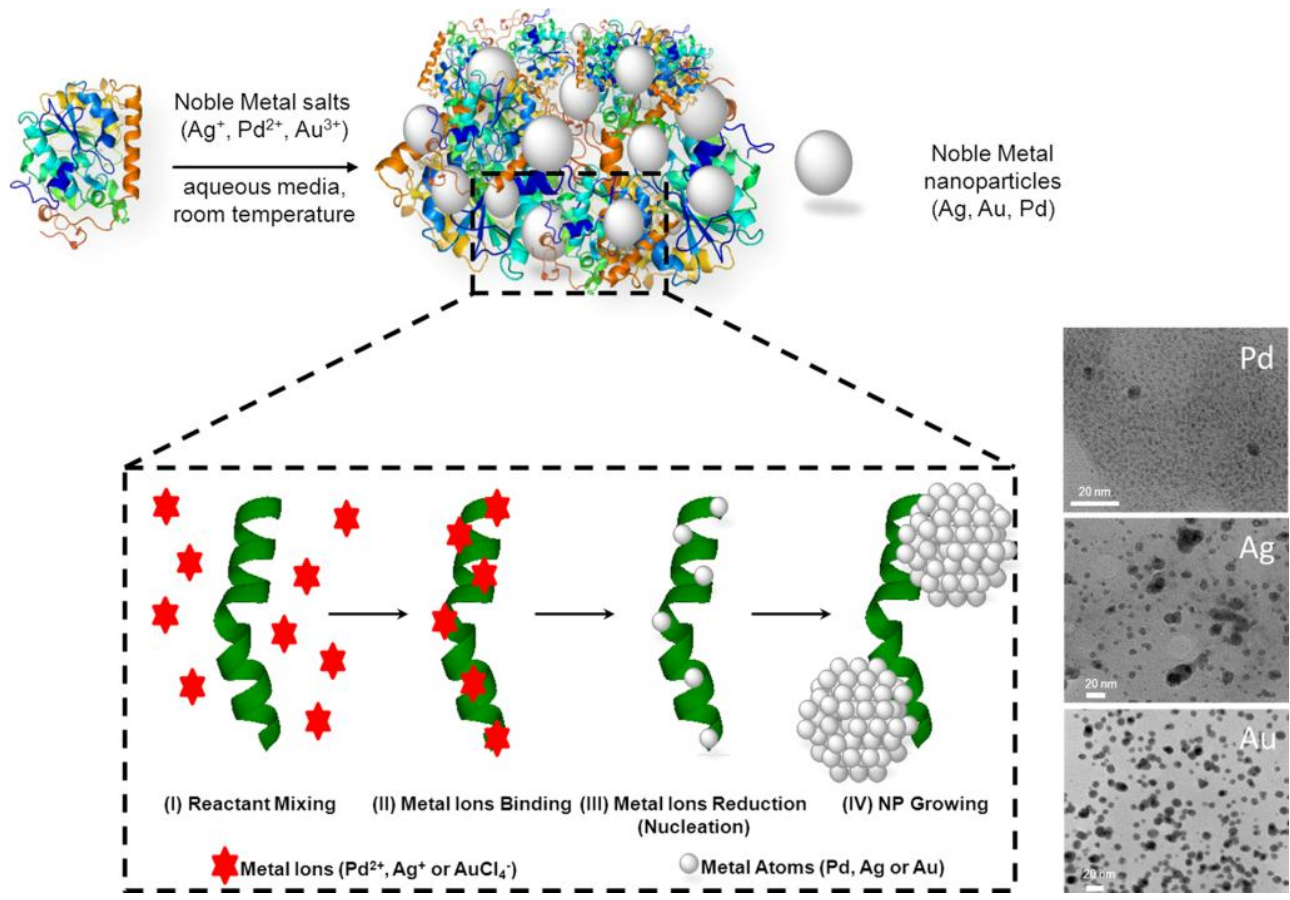

Figure 9. Preparation of metal bionanohybrids. 
This new hybrid nanocatalysts combines metallic and enzymatic catalytic activitie. The use of an enzyme in the methodology permitted the generation of small metal NPs (e.g., around $2 \mathrm{~nm}$ core size for Pd NPs) without the need for any external reducing agent, exploiting the reductive ability of the biomacromolecule (biomineralization), which moreover remains catalytically active at the end of the synthesis [22,40]. Based on the same general bio-based strategy, Das et al. reported an interesting biosynthetic route for cost-effective productions of various metal NPs ( $\mathrm{Pd}, \mathrm{Pt}$, and $\mathrm{Ag}$ ) on the surface of fungal mycelia [41]. The metal NPs were synthesized through an electrostatic interaction of metal ion precursors, followed by their reduction to nanoparticles by surface proteins finally decorating the mycelia surface in a homogeneous way. It results worth of note as, by means of this strategy, the size and shape varied depending on the metal NPs. In fact, "flower"-like branched nanoparticles were obtained in the case of $\mathrm{Pd}$ and $\mathrm{Pt}$, while $\mathrm{Ag}$ produced spheroidal nanoparticles, this structural characteristic is a key-element of their catalytic activity which is assessed in hydrogenation and Suzuki C-C coupling reactions in aqueous solution [41].

Even engineered proteins were revealed to be useful in the synthesis of precise and highly functionalized metal nanoparticles. For example, a small variant of protein A has been used as biotemplate in the one-step synthesis and biofunctionalization of AuNPs [42]. This biotemplate is composed by a thiolate ligand capable of interacting with the AuNP surface and controlling the nanoparticle nucleation and growth, thus allowing the nanoparticle size to be finely tuned. This crucial feature clearly resulted as key-advantage of this approach, which allow for high-quality AuNPs to be obtained in the water phase, and therefore avoiding the transfer from organic solvents, which usually results in a lack of long-term stability [42].

Moving a step over the well-known strategy based on the creation of metallic nanoparticles inside the cavity of hollow protein (i.e., ferritin), Jang and coworkers described the synthesis of thin-walled (ca. $40 \mathrm{~nm}$ ) $\mathrm{SnO}_{2}$ nanotubes functionalized with catalytic $\mathrm{Pt}$ and $\mathrm{Au}$ nanoparticles via a protein templating route [43]. After the creation of metal NPs inside the cavity of an apoferritin template via $\mathrm{NaBH}_{4}$ reductive strategy starting from metal salt precursors, as the prepared hybrids catalysts were used to decorate both the interior and exterior surfaces of the thin-walled $\mathrm{SnO}_{2}$ nanotubes. After calcination, the protein cage was eliminated leaving a well-dispersed layer of catalytic metal nanoparticles immobilized on nanotubes surface. Such a uniform surface distribution, resulting from the repulsion between the proteic cages before their calcination, granted a final very high surface area-to-volume ratio leading to superior catalytic performances for example in gas sensing [43].

\section{Biosynthesis of Metal Nanoparticles by Microorganisms}

Apart of the use of small molecules or even proteins, the use of entire biological units as prokaryotic or eukaryotic microorganisms have been employed for the preparation of nanoparticles of different metals ( $\mathrm{Au}, \mathrm{Ag}, \mathrm{Cd}, \mathrm{Pt}, \mathrm{Zn}, \mathrm{Fe}_{3} \mathrm{O}_{4}$ ) under moderate pressures and temperatures [44-47].

Microorganisms are capable of adsorbing and accumulating metals. They also secrete large amounts of enzymes, which are involved in the enzymatic reduction of metals ions [48,49]. Microbial synthesis of metallic nanoparticles can take place either outside or inside the cell [44], producing metal NPs, which have characteristic features similar to nanomaterials, which are synthesized chemically [14]. The localization, size or shape of the nanoparticles depend on the microorganism specie used [44].

In this way, the production of metal nanoparticles by fungi is one of the most successful strategies [42,50-53].

For example, in one of the cases, the fungus Aspergillus japonica was used for the reduction of Au (III) into Au NPs. Spherical and well distributed on fungal mycelia particles were found. The size of the particles ranges predominantly between 15 and $20 \mathrm{~nm}$. Furthermore, the nanoparticles were simultaneously immobilized on the fungus surface creating a heterogeneous hybrid with interesting catalytic properties [50].

Another example of the use of fungus was described by Loshchinina and coworkers [51]. The authors described the synthesis of AuNPs by the fungus Basidiomycete lentinus edodes. TEM experiment 
demonstrated the formation of spherical $\mathrm{Au}(0)$ nanoparticles inside the mycelia cells mostly of 5 to $15 \mathrm{~nm}$ with minor part of 30 to $50 \mathrm{~nm}$ diameter. An Au distribution map was obtained that supported these electron-dense formations to be intracellular Au nanoparticles.

This is also the first time that fungal intracellular phenol-oxidizing enzymes (laccases, tyrosinases, and Mn-peroxidases) have been involved in Au reduction to give electrostatically stabilized colloidal solutions.

Also the preparation of AuNPs has been described by Gupta and coworkers using in this case the fungus Trichoderma sp. [52]. The biosynthesis of the nanoparticles was rapid at $30^{\circ} \mathrm{C}$ using cell-free extract of the Trichoderma viride, producing extracellular AuNPs with particle size of 20-30 nm. Using Hypocrea lixii the synthesis was similar but at $100^{\circ} \mathrm{C}$, obtaining smaller nanoparticles $(<20 \mathrm{~nm})$.

The use of recombinant E. coli expressing a tyrosinase from Rhizobium etli has been described as interesting green strategy to synthesize gold nanoparticles [54]. Tyrosinase is an important enzyme in biology involved in production of melanin. The catalytic function is the oxidation of L-tyrosine to 3-(3,4-dihydroxyphenyl)-L-alanine (L-DOPA) and further to dopaquinone and melanin. In particular, eumelanin-natural pigment, which contains carboxyl, amine, hydroxyl groups, quinone and semiquinone groups-was used as agent to reduce the metals ions. In the presence of L-DOPA and gold ions, exogenous AuNPs were formed (Figure 10A). The absence of L-DOPA failed in the formation of AuNPs, demonstrating that the presence of eumelanin (generate by the enzyme with L-DOPA) is critical for the nanoparticles formation (Figure 10B). In the absence of gold ions, the transformation of L-DOPA to eumelanin was observed (Figure 10C). The TEM analysis demonstrated that the AuNPs showed a particle size average of around $12 \mathrm{~nm}$ (Figure 10D). The strategy was successfully applied to other metals obtaining NPs with a particle size between 7 and $13 \mathrm{~nm}$ [53].
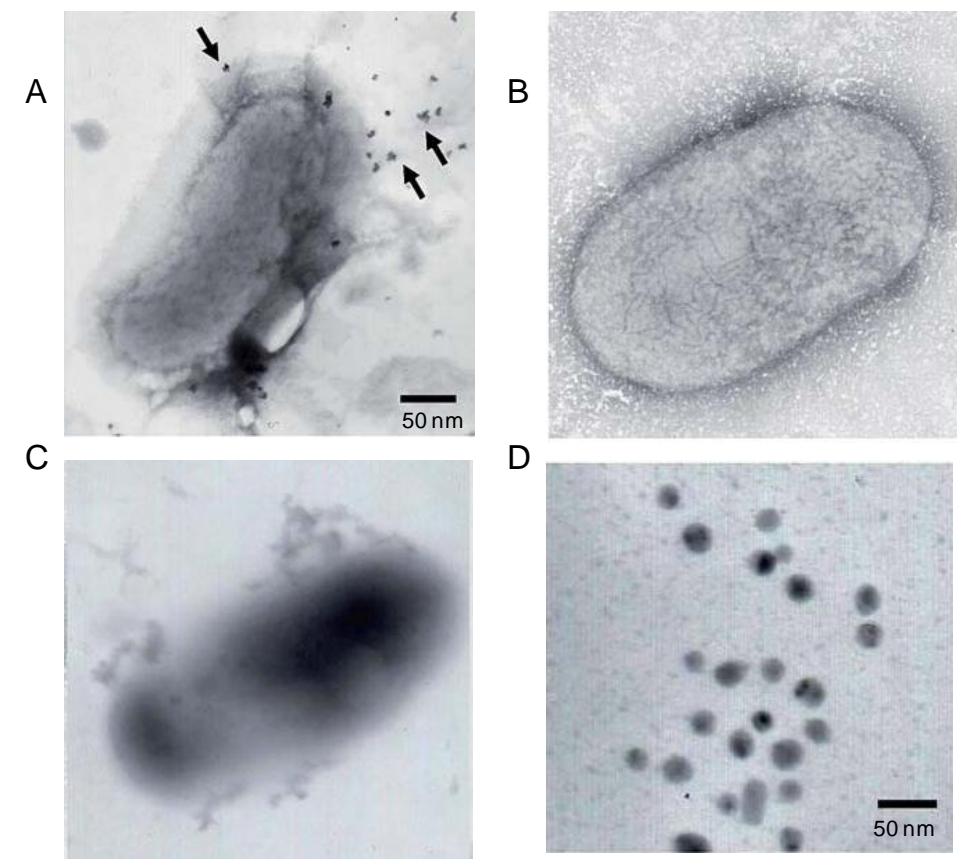

Figure 10. Eumelanine from tyrosinase induced the synthesis of gold nanoparticles. (A) TEM image of $R$. etli cell in the presence of 3-(3,4-dihydroxyphenyl)-L-alanine (L-DOPA) and Au ions; (B) TEM image of R. etli cell in the presence of Au ions; (C) TEM image of R. etli cell in the presence of L-DOPA; (D) TEM of the synthesized AuNPs. Reproduced with permission from [53]. Copyright the Royal Society of Chemistry, 2014 


\section{Biosynthesis of Metal Nanoparticles by Plant Extracts}

Another strategy used for preparation of biosynthetic green metal nanoparticles is based on the use of extract of different plants. These contain a wide amount of natural products such as polyphenylols, alkaloids, flavonoids and terpenoids (reducing and stabilizing agents), which induced the final formation of the nanoparticles. An interesting review article about that has been published recently by Banerjee and coworkers [24] and no extended description of this strategy will be present here.

However, we would like to emphasize two very recent works in the preparation of mono and bimetallic nanoparticles [12,54].

The first describes the synthesis of platinum nanoparticle (PtNP) aqueous colloid by utilizing black wattle tannin (BWT), a typical plant polyphenol (Figure 11) [54]. The hydroxyl groups of this molecule act as reducing agent but also as stabilizers and protecting the PtNPs from deactivation caused by oxygen atmosphere. The aromatic framework of BWT prevents the aggregation of the nanoparticles in contrast with the use of the most hydrophilic organic small molecules. Stable heterogeneous metallic nanoparticles under mild conditions can be then obtained by this method. Different amount of BWT were tested showing that only when $15 \mathrm{mg}$ of BWT was added, completely monodispersed Pt small nanoparticles (ca. $1.8 \mathrm{~nm}$ diameter size) were formed (Figure 11B).

A

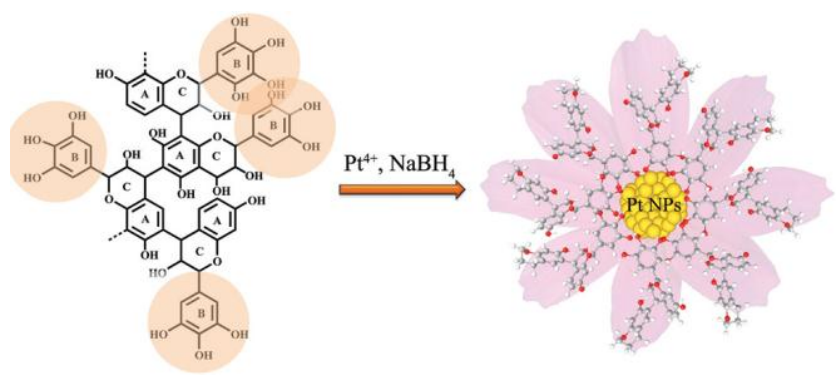

B

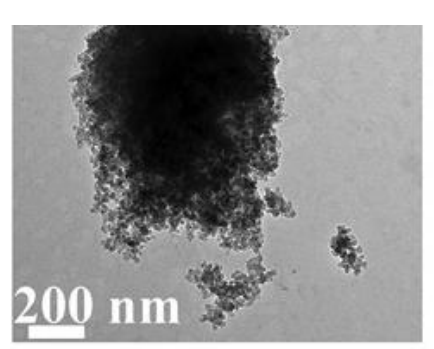

C

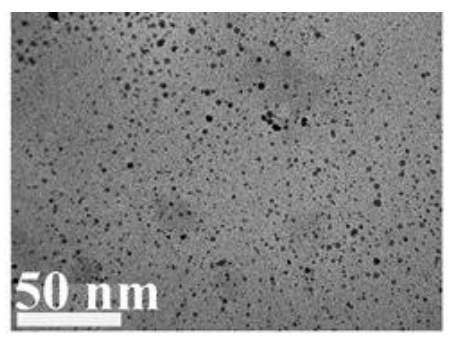

Figure 11. Synthesis of Pt nanoparticles induced by black wattle tannin (BWT). (A) Scheme of the formation of PtNPs by BWT; (B) TEM image of synthesized PtNPs using 2 mg of BWT; (C) TEM image of synthesized PtNPs using $15 \mathrm{mg}$ of BWT. Reproduced with permission from [54]. Copyright the Royal Society of Chemistry, 2016.

The second example refers to the synthesis of $\mathrm{Fe}, \mathrm{Pd}$ and Fe-Pd bimetallic nanoparticles using the medicinally potent aqueous bark extract of Ulmus davidiana [12]. As shown in the previous case, the polyols present in the plant were responsible for reducing and capping of the nanoparticles. The NPs preparation was achieved using aqueous solution of Ulmus adding firstly $\mathrm{Fe}_{2} \mathrm{O}_{3}, \mathrm{PdCl}_{2}$ or the bimetallic iron oxide and then the palladium chloride at $60^{\circ} \mathrm{C}$. The three sort NPs showed different diameter size determined by TEM. Spherical FeNPs showed $50 \mathrm{~nm}$ or PdNPs with $5 \mathrm{~nm}$-sized were obtaining using a unique metal in the synthesis. On the bimetallic, the PdNPs were adsorbed on the outer surface of the FeNPs (Figure 12A). The distribution size were 3-7 $\mathrm{nm}$ of Pd clustered around 30-70 nm of FeNPs (Figure 12B). 
A

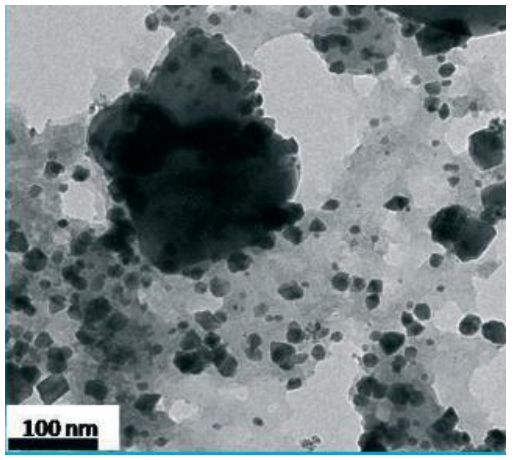

$\mathrm{B}$

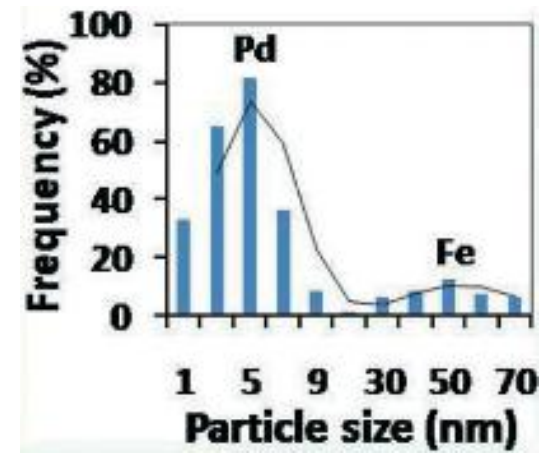

Figure 12. Characterization of Fe-Pd NPs synthesized by Ulmus davidiana. (A) TEM image of Fe-Pd NPs; (B) Particle size distribution histogram. Reproduced with permission from [12]. Copyright the Royal Society of Chemistry, 2015.

\section{Application of the Biosynthesized Metallic NPs as Nanocatalysts}

Beside the description of the metal NPs preparation, the different methods presented above have been tested on the reduction of $p$-nitrophenol to $p$-aminophenol as general model reaction in order to assess the catalytic properties of generated nanobiocatalysts.

As representative example, the catalytic constant $(k)$ and the turnover frequency (TOF) of that reaction using the CAL-B-Pd biohybrid were calculated, retrieving excellent $k$ and TOF values (0.6 $\mathrm{min}^{-1}$ and almost $150 \mathrm{~min}^{-1}$, respectively). The TOF value was the highest described in the literature for this reaction at that moment [22].

In parallel to the model aryl-amine synthesis, some of the previous synthesized heterogeneous catalysts have been successfully used in different typology of complex reactions.

Thus, the bimetallic nanoparticles formed by Fe and Pd represented a catalyst magnetically recyclable and reused in [3 + 2] cycloaddition reaction [12] (Figure 13). These Fe-Pd NPs displayed better catalytic activity, with final isolated yields from $89 \%$ to $98 \%$ for the synthesis of 12 different naphtha[1,2-b]furan-3-carboxamides and benzofuran-3-carboxamides compared to their respective monometallic nanoparticles (Figure 13).

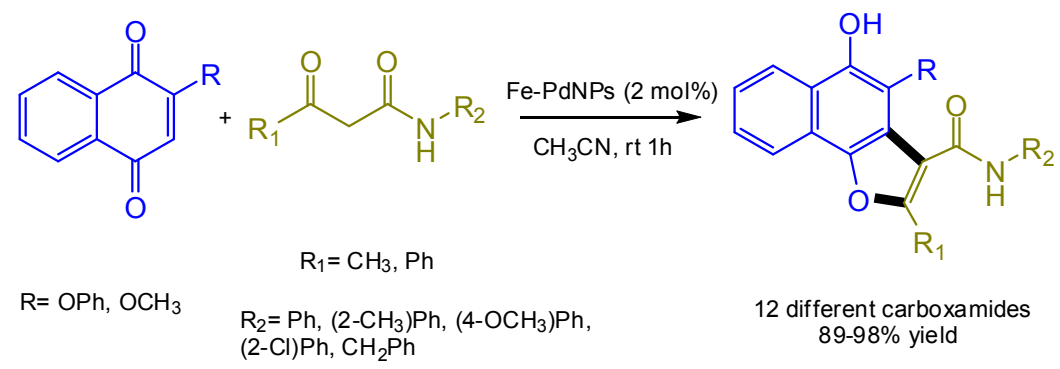

Figure 13. Synthesis of substituted carboxamides catalyzed by Fe-Pd NPs nanocatalyst.

Advantages of this heterogeneous nanocatalyst were an easy recovery using an external magnetic field, and recycling (maintaining almost complete activity after 5 times).

Another interesting example of practical usefulness is represented by the BWT-Pt colloid catalyst [54]. This nanocatalyst showed interesting activity in a series of biphasic oxidation of aromatic alcohols and aliphatic alcohols under mild aerobic conditions in aqueous media. The results were from moderate yields, for alkyl compounds, to high yield, for aromatic alcohols. The best results were obtained in the oxidation of phenylmethanol and 1-phenylethanol with more than $80 \%$ yield of product (Figure 14). The nanocatalyst was very stable and no decrease in the oxidative activity was observed after seven cycles. 


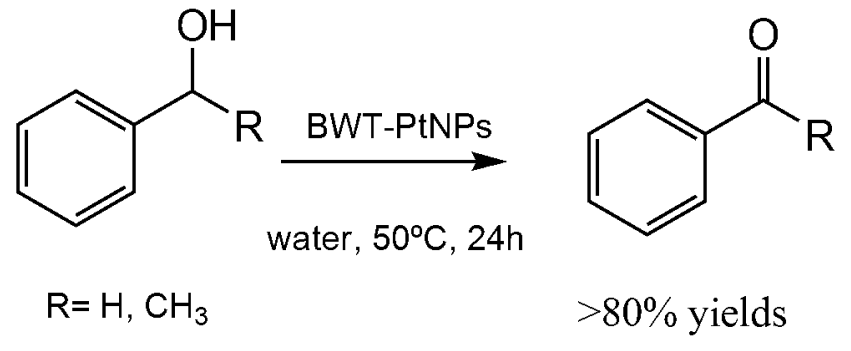

Figure 14. Oxidation of phenylalcohols by BWT-PtNPs.

The synthesis of propargylamines by a multi-component reaction has been successfully catalyzed by means of the gold-NPs-fungal hybrid bionanocatalyst [46]. These bioNPs produced different propargylamines by an A3 coupling process, a very interesting synthetic way to produce heterocyclic frameworks [55].

The high versatility of the nanocatalyst was demonstrated and over $80 \%$ yields of various propargylamine derivatives were obtained using a variety of aromatic aldehydes $\left(\mathrm{R}=\mathrm{H}, \mathrm{CH}_{3}, \mathrm{Cl}\right)$ coupled with secondary amine and alkynes after $24 \mathrm{~h}$ (Figure 15). In addition, this heterogeneous hybrid showed good recyclability.<smiles>[R]C1=[C+]CCC[CH+]C1</smiles>

AuNps-Fun Hybrid

$\mathrm{THF}, 80^{\circ} \mathrm{C}, 24 \mathrm{~h}$

$80-89 \%$ yield

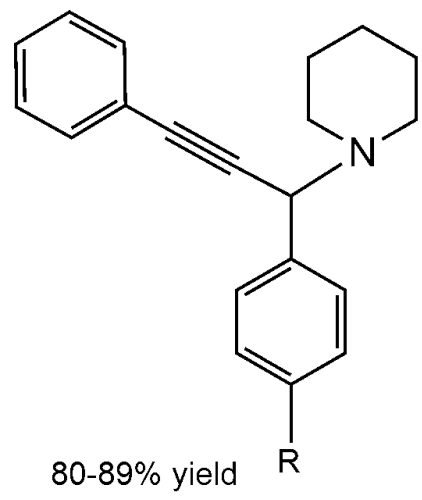

Figure 15. Multicomponent reaction catalyzed by AuNPs Hybrid.

The Pd-lipase bionanohybrid described before was successfully applied as excellent heterogeneous catalysts in C-C bond reaction [22]. This resulted in an extremely active Pd-catalyst in the Suzuki reaction, forming the biphenyl in $>99 \%$ conversion using $p p b$ of catalyst (Figure 16). Furthermore, the reaction was performed in pure water so making this organic reaction a green chemical process. A recyclable catalyst was obtained, used five times conserving almost the activity intact.

The particular advantage of this catalyst is that it conserved the native enzymatic activity, so it was successfully applied in the dynamic kinetic resolution of rac-phenylethylamine in organic solvent, a tandem catalytic process (both enzymatic and Pd catalysis acting at the same time) (Figure 16). The bionanohybrid quantitatively produced the enantiopure $(R)$-benzylamide with $e e>99 \%$. Even in this case, the recyclability of the catalyst was excellent.

Finally, also the previously described "flower"-like branched Pd nanoparticles were used as heterogeneous catalyst in the Suzuki reaction of formation of biaryl with satisfactory results ( $99 \%$ conversion) [41]. 


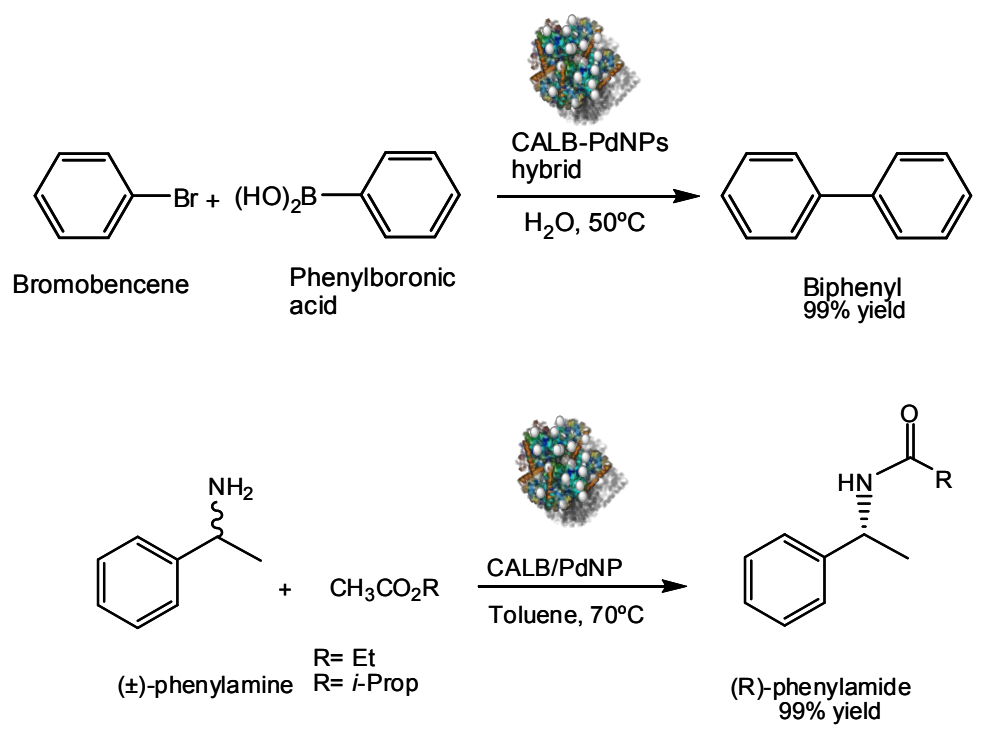

Figure 16. Catalytic applications of CAL-B-PdNPs hybrid.

\section{Conclusions}

In conclusion, this review showed the most recent different strategies used for the biosynthesis of metal nanoparticles. The application of biological entities represents an interesting and green solution for the environmentally friendly synthesis of these nanoparticles. The use of enzymes as biomolecule permits the design of more precise nanostructures for many interesting chemical applications and it allows combination of one or more metallic activities together with enzymatic catalytic ones (excellent for cascade processes). Therefore, the development of newer and more efficient bio-methodologies for the creation of nanobiohybrids will be a future issue. Together with that, the reviewed examples showed also the excellent catalytic application of these heterogeneous nanocatalysts demonstrating the tremendous potential of their use in organic synthesis.

Acknowledgments: This work was supported by the Spanish National Research Council (CSIC). The author thanks the Ramon Areces Foundation for financial support. M.F also thanks the MINECO for the research grant SAF2014-59118-JIN (Programa Estatal de Investigación, Desarrollo e Innovación Orientada a los Retos de la Sociedad 2014: "Proyectos de I+D+i para jóvenes investigadores"), and co-funding by Fondo Europeo de Desarrollo Regional (FEDER).

Conflicts of Interest: The authors declare no conflict of interest.

\section{References}

1. Zhang, F.; Nangreave, J.; Liu, Y.; Yan, H. Structural DNA nanotechnology: State of the art and future perspective. J. Am. Chem. Soc. 2014, 136, 11198-11211. [CrossRef] [PubMed]

2. Mo, R.; Jiang, T.; Di, J.; Tai, W.; Gu, Z. Emerging micro- and nanotechnology based synthetic approaches for insulin delivery. Chem. Soc. Rev. 2014, 43, 3595-3629. [CrossRef] [PubMed]

3. Han, X.; Zheng, Y.; Munro, C.J.; Ji, Y.; Braunschweig, A.B. Carbohydrate nanotechnology: Hierarchical assembly using nature's other information carrying biopolymers. Curr. Opin. Biotechnol. 2015, 34, 41-47. [CrossRef] [PubMed]

4. Dai, Y.; Wang, Y.; Liu, B.; Yang, Y. Metallic nanocatalysis: An accelerating seamless integration with nanotechnology. Small 2015, 11, 268-289. [CrossRef] [PubMed]

5. Zhou, W.; Gao, X.; Liu, D.; Chen, X. Gold Nanoparticles for in Vitro Diagnostics. Chem. Rev. 2015, 115, 10575-10636. [CrossRef] [PubMed]

6. DaCosta, M.V.; Doughan, S.; Han, Y.; Krull, U.J. Lanthanide upconversion nanoparticles and applications in bioassays and bioimaging: A review. Anal. Chim. Act. 2014, 832, 1-33. [CrossRef] [PubMed] 
7. Shi, D.; Sadat, M.E.; Dunn, A.W.; Mast, D.B. Photo-fluorescent and magnetic properties of iron oxide nanoparticles for biomedical applications. Nanoscale 2015, 7, 8209-8232. [CrossRef] [PubMed]

8. Goldberg, M.S. Immunoengineering: How nanotechnology can enhance cancer immunotherapy. Cell 2015, 161, 201-204. [CrossRef] [PubMed]

9. Dong, X.-Y.; Gao, Z.-W.; Yang, K.-F.; Zhang, W.-Q.; Xu, L.-W. Nanosilver as a new generation of silver catalysts in organic transformations for efficient synthesis of fine chemicals. Catal. Sci. Technol. 2015, 5, 2554-2574. [CrossRef]

10. Filice, M.; Palomo, J.M. Cascade reactions catalyzed by bionanostructures. ACS Catal. 2014, 4, 1588-1598. [CrossRef]

11. Serna, P.; Corma, A. Transforming nano metal nonselective particulates into chemoselective catalysts for hydrogenation of substituted nitrobenzenes. ACS Catal. 2015, 5, 7114-7121. [CrossRef]

12. Mishra, K.; Basavegowda, N.; Lee, Y.R. Biosynthesis of Fe, Pd, and Fe-Pd bimetallic nanoparticles and their application as recyclable catalysts for [3 + 2] cycloaddition reaction: A comparative approach. Catal. Sci. Technol. 2015, 5, 2612-2621. [CrossRef]

13. Aditya, T.; Pal, A.; Pal, T. Nitroarene reduction: A trusted model reaction to test nanoparticle catalysts. Chem. Commun. 2015, 51, 9410-9431. [CrossRef] [PubMed]

14. MubarakAli, D.; Gopinath, V.; Rameshbabu, N.; Thajuddin, N. Synthesis and characterization of CdS nanoparticles using C-phycoerythrin from the marine cyanobacteria. Mater. Lett. 2012, 74, 8-11. [CrossRef]

15. Saldan, I.; Semenyuk, Y.; Marchuk, I.; Reshetnyak, O. Chemical synthesis and application of palladium nanoparticles. J. Mat. Sci. 2015, 50, 2337-2354. [CrossRef]

16. Gutiérrez, L.; Costo, R.; Grüttner, C.; Westphal, F.; Gehrke, N.; Heinke, D.; Fornara, A.; Pankhurst, Q.A.; Johansson, C.; Veintemillas-Verdaguer, S.; et al. Synthesis methods to prepare single- and multi-core iron oxide nanoparticles for biomedical applications. Dalton Trans. 2015, 44, 2943-2952. [CrossRef] [PubMed]

17. Shervani, Z.; Yamamoto, Y. Carbohydrate-directed synthesis of silver and gold nanoparticles: Effect of the structure of carbohydrates and reducing agents on the size and morphology of the composites. Carbohydr. Res. 2011, 346, 651-658. [CrossRef] [PubMed]

18. Yokota, S.; Kitaoka, T.; Opietnik, M.; Rosenau, T.; Wariishi, H. Synthesis of gold nanoparticles for in situ conjugation with structural carbohydrates. Angew. Chem. Int. Ed. 2008, 47, 9866-9869. [CrossRef] [PubMed]

19. Engelbrekt, C.; Sørensen, K.H.; Zhang, J.; Welinder, A.C.; Jensen, P.S.; Ulstrup, J. Green synthesis of gold nanoparticles with starch-glucose and application in bioelectrochemistry. J. Mater. Chem. 2009, 19, 7839-7847. [CrossRef]

20. Care, A.; Bergquist, P.L.; Sunna, A. Solid-binding peptides: Smart tools for nanobiotechnology. Trends Biotechnol. 2015, 33, 259-268. [CrossRef] [PubMed]

21. Tan, Y.N.; Lee, J.Y.; Wang, D.I.C. Uncovering the design rules for peptide synthesis of metal nanoparticles. J. Am. Chem. Soc. 2010, 132, 5677-5686. [CrossRef] [PubMed]

22. Filice, M.; Marciello, M.; Morales, M.P.; Palomo, J.M. Synthesis of heterogeneous enzyme-metal nanoparticle biohybrids in aqueous media and their applications in $\mathrm{C}-\mathrm{C}$ bond formation and tandem catalysis. Chem. Commun. 2013, 49, 6876-6878. [CrossRef] [PubMed]

23. Mittal, A.K.; Chisti, Y.; Banerjee, U.C. Synthesis of metallic nanoparticles using plant extracts. Biotechnol. Adv. 2013, 31, 346-356. [CrossRef] [PubMed]

24. Chinnadayyala, S.R.; Santhosh, M.; Singh, N.K.; Goswami, P. Alcohol oxidase protein mediated in situ synthesized and stabilized gold nanoparticles for developing amperometric alcohol biosensor. Biosen. Bioelec. 2015, 69, 151-161. [CrossRef] [PubMed]

25. Hulkoti, N.I.; Taranath, T.C. Biosynthesis of nanoparticles using microbes-A review. Colloids Surf. B 2014, 121, 474-483. [CrossRef] [PubMed]

26. Mashwani, Z.-U.-R.; Khan, T.; Khan, M.A.; Nadhman, A. Synthesis in plants and plant extracts of silver nanoparticles with potent antimicrobial properties: Current status and future prospects. App. Microb. Biotechnol. 2015, 99, 9923-9934. [CrossRef] [PubMed]

27. Sousa, A.A.; Hassan, S.A.; Knittel, L.L.; Balbo, A.; Aronova, M.A.; Brown, P.H.; Schuck, P.; Leapman, R.D. Biointeractions of ultrasmall glutathione-coated gold nanoparticles: Effect of small size variations. Nanoscale 2016, 8, 6577-6588. [CrossRef] [PubMed] 
28. Jung, J.; Park, S.; Hong, S.; Ha, M.W.; Park, H.-G.; Lee, H.-J.; Park, Y.; Park, Y. Synthesis of gold nanoparticles with glycosides: Synthetic trends based on the structures of glycones and aglycones. Carbohydr. Res. 2014, 386, 57-61. [CrossRef] [PubMed]

29. Raman, R.P.; Parthiban, S.; Srinithya, B.; Vinod, V.; Savarimuthu, K.; Anthony, P.; Sivasubramanian, A.; Muthuraman, M.S. Biogenic silver nanoparticles synthesis using the extract of the medicinal plant Clerodendron serratum and its in vitro antiproliferative Activity. Mat. Lett. 2015, 160, 400-403. [CrossRef]

30. Saint-Cricq, P.; Wang, J.; Sugawara-Narutaki, A.; Shimojima, A.; Okubo, T. A new synthesis of well-dispersed, core-shell Ag@SiO mesoporous nanoparticles using amino acids and sugars. J. Mater. Chem. B 2013, 1, 2451-2454. [CrossRef]

31. Kitaoka, T.; Yokota, S.; Opietnik, M.; Rosenau, T. Synthesis and bio-applications of carbohydrate-gold nanoconjugates with nanoparticle and nanolayer forms. Mat. Sci. Eng. C 2011, 31, 1221-1229. [CrossRef]

32. Mishra, N.K.; Kumar, V.; Joshi, K.B. Fabrication of gold nanoparticles on biotin-ditryptophan scaffold for plausible biomedical applications. RSC Adv. 2015, 5, 64387-64394. [CrossRef]

33. Kracht, S.; Messerer, M.; Lang, M.; Eckhardt, S.; Lauz, M.; Grobty, B.; Fromm, K.M.; Giese, B. Electron Transfer in Peptides: On the Formation of Silver Nanoparticles. Angew. Chem. Int. Ed. 2015, 54, 2912-2916. [CrossRef] [PubMed]

34. Gulsuner, H.U.; Ceylan, H.; Guler, M.O.; Tekinay, A.B. Multi-domain short peptide molecules for in situ synthesis and biofunctionalization of gold nanoparticles for integrin-targeted cell uptake. ACS Appl. Mater. Interfaces 2015, 7, 10677-10683. [CrossRef] [PubMed]

35. Belser, K.; Slenters, T.V.; Ofumbidzai, C.; Upert, G.; Mirolo, L.; Fromm, K.M.; Wennermers, H. Silver nanoparticle formation in different sizes induced by peptides identified within split-and-mix libraries. Angew. Chem. Int. Ed. 2009, 48, 3661-3664. [CrossRef] [PubMed]

36. Tomizaki, K.-Y.; Kubo, S.; Ahn, S.-A.; Satake, M.; Imai, T. Biomimetic alignment of zinc oxide nanoparticles along a peptide nanofiber. Langmuir 2012, 28, 13459-13466. [CrossRef] [PubMed]

37. Naik, R.R.; Stringer, S.J.; Agarwal, G.; Jones, S.E.; Stone, M.O. Biomimetic synthesis and patterning of silver nanoparticles. Nat. Mater. 2002, 1, 169-172. [CrossRef] [PubMed]

38. Gholami-Shabani, M.; Shams-Ghahfarokhi, M.; Gholami-Shabani, Z.; Akbarzadeh, A.; Riazi, G.; Ajdari, S.; Amani, A.; Razzaghi-Abyaneh, M. Enzymatic synthesis of gold nanoparticles using sulfite reductase purified from Escherichia coli: A green eco-friendly approach. Process Biochem. 2015, 50, 1076-1085. [CrossRef]

39. Das, S.K.; Khan, M.R.; Guhab, A.K.; Naskar, N. Bio-inspired fabrication of silver nanoparticles on nanostructured silica: Characterization and application as a highly efficient hydrogenation catalyst. Green Chem. 2013, 15, 2548-2557. [CrossRef]

40. Cuenca, T.; Filice, M.; Palomo, J.M. Palladium nanoparticles enzyme aggregate (PANEA) as efficient catalyst for Suzuki-Miyaura reaction in aqueous media. Enzyme Microb. Technol. 2016, in press. [CrossRef]

41. Das, S.K.; Parandhaman, T.; Pentela, N.; Islam, A.K.M.M.; Mandal, A.B.; Mukherjee, M. Understanding the biosynthesis and catalytic activity of $\mathrm{Pd}, \mathrm{Pt}$, and $\mathrm{Ag}$ nanoparticles in hydrogenation and Suzuki coupling reactions at the nano-bio interface. J. Phys. Chem. C 2014, 118, 24623-24632. [CrossRef]

42. Colombo, M.; Mazzucchelli, S.; Collico, V.; Avvakumova, S.; Pandolfi, L.; Corsi, F.; Porta, F.; Prosperi, D. Protein-assisted one-pot synthesis and biofunctionalization of spherical gold nanoparticles for selective targeting of cancer cells. Angew. Chem. Int. Ed. 2012, 51, 9272-9275. [CrossRef] [PubMed]

43. Jang, J.-S.; Kim, S.-J.; Choi, S.-J.; Kim, N.-H.; Hakim, M.; Rothschild, A.; Kim, I.-D. Thin-walled $\mathrm{SnO}_{2}$ nanotubes functionalized with $\mathrm{Pt}$ and Au catalysts via the protein templating route and their selective detection of acetone and hydrogen sulfide molecules. Nanoscale 2015, 7, 16417-16426. [CrossRef] [PubMed]

44. Moghaddam, A.B.; Namvar, F.; Moniri, M.; Md Tahir, P.; Azizi, S.; Mohamad, R. Nanoparticles biosynthesized by fungi and yeast: A review of their preparation, properties, and medical applications. Molecules 2015, 20, 16540-16565. [CrossRef] [PubMed]

45. Pereira, L.; Mehboob, F.; Stams, A.J.M.; Mota, M.M.; Rijnaarts, H.H.M.; Alves, M.M. Metallic nanoparticles: Microbial synthesis and unique properties for biotechnological applications, bioavailability and biotransformation. Crit. Rev. Biotechnol. 2015, 35, 114-128. [CrossRef] [PubMed]

46. Chitam, H.; Zhu, N.; Shang, R.; Shi, C.; Cui, J.; Sohoo, I.; Wu, P.; Cao, Y. Biorecovery of palladium as nanoparticles by Enterococcus faecalis and its catalysis for chromate reduction. Chem. Eng. J. 2016, 288, 246-254. 
47. Lloyd, J.R.; Byrne, J.M.; Coker, V.S. Biotechnological synthesis of functional nanomaterials. Curr. Opin. Biotechnol. 2011, 22, 509-515. [CrossRef] [PubMed]

48. Zhang, X.; Yan, S.; Tyagi, R.D.; Surampalli, R.Y. Synthesis of nanoparticles by microorganisms and their application in enhancing microbiological reaction rates. Chemosphere 2011, 82, 489-494. [CrossRef] [PubMed]

49. Huang, C.P.; Juang, C.P.; Morehart, K.; Allen, L. The removal of Cu (II) from dilute aqueous solutions by Saccharomyces cerevisiae. Water Res. 1990, 24, 433-439. [CrossRef]

50. Bhargavaa, A.; Jaina, N.; Gangopadhyayb, S.; Panwara, J. Development of gold nanoparticle-fungal hybrid based heterogeneous interface for catalytic applications. Process Biochem. 2015, 50, 1293-1300. [CrossRef]

51. Vetchinkina, E.P.; Loshchinina, E.A.; Burov, A.M.; Dykman, L.A.; Nikitina, V.E. Enzymatic formation of gold nanoparticles by submerged culture of the basidiomycete Lentinus edodes. J. Biotechnol. 2014, 182-183, 37-45. [CrossRef] [PubMed]

52. Mishra, A.; Kumari, M.; Pandey, S.; Chaudhry, V.; Gupta, K.C.; Nautiyal, C.S. Biocatalytic and antimicrobial activities of gold nanoparticles synthesized by Trichoderma sp. Bioresour. Technol. 2014, 166, 235-242. [CrossRef] [PubMed]

53. Tsai, Y.-J.; Ouyang, C.-Y.; Ma, S.-Y.; Tsai, D.-Y.; Tsengand, H.-W.; Yeh, Y.-C. Biosynthesis and display of diverse metal nanoparticles by recombinant Escherichia coli. RSC Adv. 2014, 4, 58717-58719. [CrossRef]

54. Mao, H.; Liao, Y.; Ma, J.; Zhao, S.L.; Huo, F.W. Water-soluble metal nanoparticles stabilized by plant polyphenols for improving the catalytic properties in oxidation of alcohols. Nanoscale 2016, 8, 1049-1054. [CrossRef] [PubMed]

55. Peshkov, V.A.; Pereshivko, O.P.; Van der Eycken, E.V. A walk around the $\mathrm{A}^{3}$-coupling. Chem. Soc. Rev. 2012, 41, 3790-3807. [CrossRef] [PubMed]

(C) 2016 by the authors; licensee MDPI, Basel, Switzerland. This article is an open access article distributed under the terms and conditions of the Creative Commons Attribution (CC-BY) license (http://creativecommons.org/licenses/by/4.0/). 